\title{
Correlation of physical and cognitive impairment in diabetic and hypertensive frail older adults
}

\author{
Pasquale Mone ${ }^{1,2,3^{*}}$, Jessica Gambardella ${ }^{1,4}$, Angela Lombardi ${ }^{1}$, Antonella Pansini ${ }^{5}$, Stefano De Gennaro ${ }^{3}$, \\ Anna Luisa Leo ${ }^{3}$, Michele Famiglietti ${ }^{3}$, Anna Marro ${ }^{5}$, Maria Morgante ${ }^{5}$, Salvatore Frullone ${ }^{3}$, \\ Antonio De Luca ${ }^{2}$ and Gaetano Santulli $i^{1,4,6^{*}}$
}

\begin{abstract}
Background: Diabetes and hypertension are common in older adults and represent established risk factors for frailty. Frailty is a multidimensional condition due to reserve loss and susceptibility to stressors with a high risk of death, hospitalizations, functional and cognitive impairment. Comorbidities such as diabetes and hypertension play a key role in increasing the risk of mortality, hospitalization, and disability. Moreover, frail patients with diabetes and hypertension are known to have an increased risk of cognitive and physical impairment. Nevertheless, no study assessed the correlation between physical and cognitive impairment in frail older adults with diabetes and hypertension.

Methods: We evaluated consecutive frail older patients with diabetes and hypertension who presented at ASL (local health unit of the Italian Ministry of Health) Avellino, Italy, from March 2021 to October 2021. The inclusion criteria were: a previous diagnosis of diabetes and hypertension with no evidence of secondary causes; age > 65 years; a frailty status; Montreal Cognitive Assessment (MoCA) score $<26$.

Results: 179 patients successfully completed the study. We found a strong and significant correlation between MoCA score and 5 -m gait speed test $(r: 0.877 ; p<0.001)$. To further verify our results, we performed a linear multivariate analysis adjusting for potential confounding factors, with MoCA score as dependent variable, which confirmed the significant association with glycemia $(p<0.001)$.
\end{abstract}

Conclusions: This is the first study showing a significant correlation between 5-m gait speed test and MoCA score in frail diabetic and hypertensive older adults.

Keywords: Diabetes, Hypertension, Frailty, Cognitive impairment, Physical impairment

\section{Background}

Hypertension and Type 2 Diabetes Mellitus (herein called diabetes) are very common in older adults [1-8]. Furthermore, both disorders are well-known risk factors

\footnotetext{
*Correspondence: pasquale.mone@unicampania.it; gsantulli001@gmail.com ${ }^{1}$ Department of Medicine, Einstein Institute for Aging Research, Einstein-Mount Sinai Diabetes Research Center (ES-DRC), The Fleischer Institute for Diabetes and Metabolism (FIDAM), Albert Einstein College of Medicine, New York, NY, USA

Full list of author information is available at the end of the article
}

for frailty [9-14], a multidimensional condition due to reserve loss and susceptibility to stressors with a high risk of death, hospitalizations, functional and cognitive impairment [15-19]. Evaluating and properly treating comorbidities and complications is crucial to reduce the incidence of cognitive and physical impairment; hence, clinical evaluation is the main goal to obtain an early diagnosis and a timely treatment to prevent adverse events [20-26]. Of note, frail patients with diabetes and hypertension are known to have a higher risk of cognitive 
and physical impairment [27-34]. Nevertheless, no report hitherto evaluated the actual correlations between physical and cognitive impairment in frail older adults with diabetes and hypertension. Our study, thus, aimed to investigate the relationships between physical and cognitive impairment in this previously reported population.

\section{Methods}

We recruited consecutive frail older patients with diabetes and hypertension from March 2021 to October 2021 at ASL (local health unit of the Italian Ministry of Health) Avellino, Italy. Inclusion criteria were: age $>65$ years; a previous diagnosis of diabetes and hypertension with no evidence of secondary causes; a frailty status; Montreal Cognitive Assessment (MoCA) score < 26. Exclusion Criteria were: Age $<65$ years; absence of frailty status; absence of diabetes and hypertension; previous cerebrovascular events; left ventricular ejection fraction $<25 \%$, with previous myocardial infarction or previous PPCI and/or coronary artery by-pass grafting.

All patients underwent blood pressure measurement, heart rate (HR) evaluation, and blood analysis to assess glycemia and HbA1c. An informed consent was signed by each patient (or legal representative). Research was performed according to the 1975 Declaration of Helsinki and its later amendments. The Institutional Review Board of Campania Nord approved the protocol.

\section{Assessment of cognitive function}

Global cognitive function was assessed via MoCA test. This cognitive test covers many cognitive skills, scores range from 0 to 30, and cognitive impairment is defined by values $<26$. This test assesses the main cognitive areas: immediate and delayed memory (free and cued recall), language, visuoperceptual and visuospatial capacities, motor planning, executive function, attention, and cognitive judgment. Instead, MMSE scores are influenced by demographic variables such as age and years of education: subjects with higher education levels have better results than subjects with lower levels. In particular, older adults show worst performances in MMSE scores that are age-dependent [35-37]. MoCA test is more specific to evaluate cognitive domains (attention, concentration, memory, language, calculation, orientation and executive functions) and is considered the best test to detect mild cognitive impairment $[38,39]$.

\section{Frailty evaluation}

A physical frailty assessment was performed following the Fried Criteria, as previously described [23, 24]. A diagnosis of frailty status was made with at least three points out of five, whereas patients having one or two points were considered pre-frails and, as such, excluded:

-Low physical activity level (a weighted score of kilocalories expended per week was calculated at baseline based on each participant's report. The lowest quintile of physical activity was identified for each gender).

-Weight loss (unintentional loss $\geq 4.5 \mathrm{~kg}$ in the past year).

-Exhaustion (poor endurance and energy, selfreported). Self-reported exhaustion, identified by two questions from the CES-D scale, is associated with stage of exercise reached in graded exercise testing, as an indicator of $\mathrm{O}_{2} \max$, and is predictive of cardiovascular disease.

-Weakness (handgrip strength in the lowest 20\% quintile at baseline, adjusted for sex and body mass index).

-Slowness (walking speed under the lowest quintile adjusted for sex and height).

Additionally, we performed a 5-m gait speed test in all patients before discharge. This test is among the most used approaches to measure the time required to walk a short distance at a comfortable pace; an altered gait speed test has been associated with impairments in lower-extremity muscle function, as well as neurosensory and cardiopulmonary dysfunction [40, 41]. Previous reports have shown that performing a $5-\mathrm{m}$ gait speed test alone is sufficient to evaluate the frailty status in patients with cardiovascular diseases [40, 42-45].

\section{Statistical analysis}

Data are presented as mean \pm SD. Based on our preliminary findings in a pilot study (rho: 0.26 ), we calculated the number of patients required for the study to reject the null hypothesis $95 \%$ of the time (i.e., with a one-tailed type II error rate of 0.05) with a two-tailed type I error at the 0.05 level of significance; the sample size was calculated via GPOWER software, yielding a minimum size of 151 patients. We applied a dispersion model correlating MoCA score and 5-m gait speed test; we also performed a linear regression analysis with MoCA score as dependent variable adjusting for potential confounding factors, including age, sex, BMI, blood pressure, HR, glycemia, HbA1c, and comorbidities. All calculations were computed using the SPSS 26 software.

\section{Results}

We evaluated 248 frail elders with diabetes and hypertension. Since 34 patients were unwilling to provide clinical information, and 35 subjects did not meet inclusion 
criteria, 179 patients met the inclusion and exclusion criteria (Fig. 1). The clinical characteristics of our study group are reported in Table 1 . There were no significant differences in age, BMI, sex distribution, smoking habits, are reported in between the two groups (Table 1).

Concerning comorbidities, which are of particular importance in a population like the one investigated in our study, we detected COPD in $30.7 \%$ of patients, CKD in $35.8 \%$, HF in $37.5 \%$,). The use of diuretics, angiotensin-converting enzyme inhibitors, beta-blockers, and calcium blockers was also similar between the two groups (Table 1).

We found a significant correlation between MoCA score and $5-\mathrm{m}$ gait speed test ( $\mathrm{r}: 0.877 ; \mathrm{p}<0.001$ ), as shown in Fig. 2. In the effort to confirm our results, we performed a linear multivariate analysis with MoCA score as the dependent variable, adjusting for potential confounding factors, including age, sex, BMI, blood pressure, HR, glycemia, HbA1c, and comorbidities. We observed (Table 2) a significant association with glycemia and age $(\mathrm{p}<0.001)$; furthermore, we observed significant results for sex (0.002), HR (p: 0.003), HF (p 0.010), and CKD (p 0.022).

\section{Discussion}

To the best of our knowledge, this study is the first to highlight a strong correlation between physical and cognitive impairment in hypertensive and diabetic elderly patients. Previous studies had highlighted the interaction between physical and cognitive function [46, 47]; however, no study had hitherto investigated this relationship in frail elders with diabetes and hypertension.

The management of frailty in older adults is very debated; comorbidities such as diabetes and

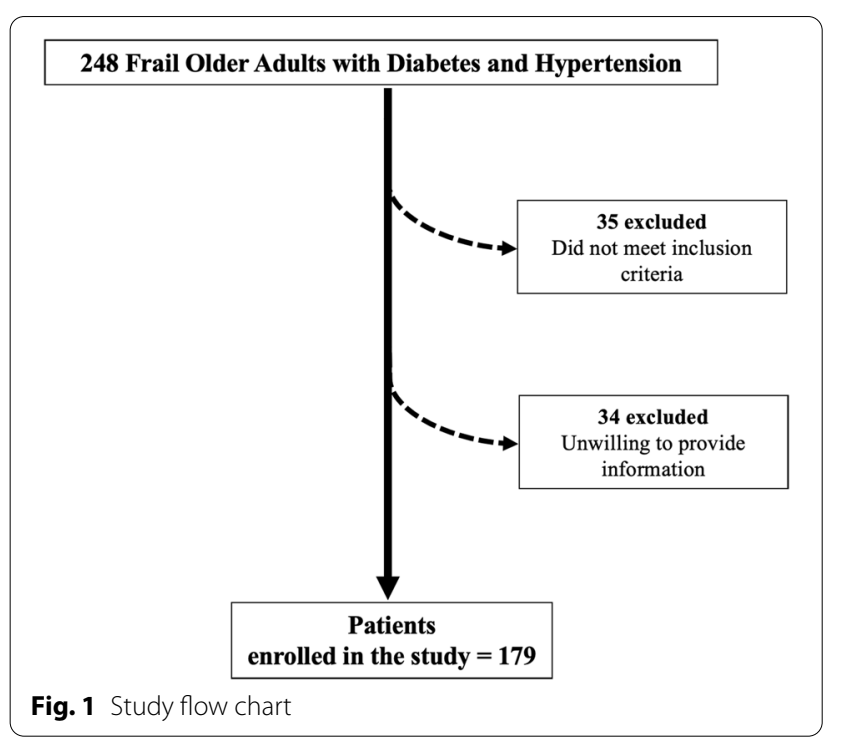

Table 1 Clinical characteristics of the patients

\begin{tabular}{ll}
\hline & Values \\
\hline $\mathrm{N}$ & 179 \\
Sex (M/F) & $74 / 105$ \\
Mean age (years) & $81.0 \pm 8.5$ \\
BMI (kg/m²) & $28.5 \pm 1.4$ \\
SBP (mmHg) & $129.3 \pm 11.7$ \\
DBP (mmHg) & $77.5 \pm 9.5$ \\
Heart rate (bpm) & $81.0 \pm 9.0$ \\
5mGS test (m/s) & $0.6 \pm 0.1$ \\
Comorbidities & \\
COPD & $55(30.7)$ \\
CKD & $64(35.8)$ \\
HF & $66(37.5)$ \\
Hyperlipidemia & $70(39.1)$ \\
Laboratory analyses & \\
Plasma glucose (mg/dl) & $166.0 \pm 58.67$ \\
HbA1c (mmol/l) & $7.5 \pm 0.7$ \\
Global cognitive function & \\
MoCA & $20.59 \pm 3.8$ \\
Fried Criteria & \\
Weight loss & $130(72.6)$ \\
Exhaustion & $57(31.9)$ \\
Low physical activity & $55(30.7)$ \\
Slowness & $141(78.8)$ \\
Weakness & $154(86.0)$ \\
\hline Data ar means &
\end{tabular}

Data are means \pm SD for continuous variables or $n(\%)$ for categorical variables 5 MGS 5-meter gait speed, $B M I$ body mass index, CKD chronic kidney disease, COPD chronic obstructive pulmonary disease, $D B P$ diastolic blood pressure, $\mathrm{HbA1c}$ glycated hemoglobin, $\mathrm{HF}$ heart failure, MoCA Montreal Cognitive Assessment, SBP systolic blood pressure

hypertension are well recognized to play key roles in increasing the risk of mortality, hospitalization and disability. Indeed, both of them are functionally linked to endothelial dysfunction, inflammation, atherosclerosis, and oxidative stress [48-55] driving cognitive and physical impairment in a complex syndrome such as frailty [56-63].

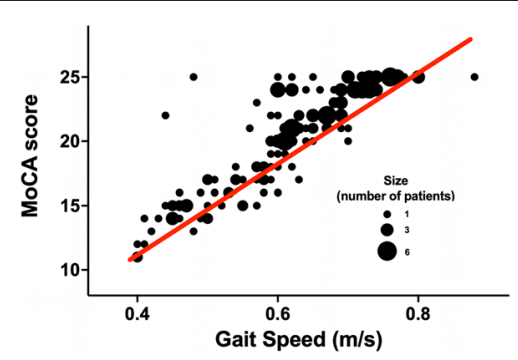

Fig. 2 Dispersion model (bubble chart) between MoCA score and gait speed test $(r: 0.877 ; p<0.001)$ 
Table 2 Multivariate Regression Analysis using the MoCA score as the dependent variable

\begin{tabular}{|c|c|c|c|c|c|c|c|}
\hline & \multirow[t]{2}{*}{ B } & \multirow[t]{2}{*}{ Standard error } & \multirow[t]{2}{*}{ Beta } & \multirow[t]{2}{*}{$\mathbf{t}$} & \multirow[t]{2}{*}{$\mathbf{p}$} & \multicolumn{2}{|c|}{ 95\% Confidence Interval } \\
\hline & & & & & & Lower bound & Upper bound \\
\hline Age & -0.126 & 0.038 & -0.176 & -3.306 & $<0.001$ & -0.202 & -0.051 \\
\hline Sex & -1.275 & 0.402 & -0.165 & -3.171 & 0.002 & -2.069 & -0.481 \\
\hline BMI & -0.153 & 0.117 & -0.068 & -1.312 & 0.191 & -0.383 & 0.077 \\
\hline SBP & -0.049 & 0.025 & -0.101 & -1.944 & 0.054 & -0.099 & 0.001 \\
\hline DBP & 0.037 & 0.030 & 0.063 & 1.237 & 0.218 & -0.022 & 0.096 \\
\hline $\mathrm{HR}$ & 0.070 & 0.023 & 0.163 & 3.053 & 0.003 & 0.025 & 0.116 \\
\hline Glycemia & -0.037 & 0.004 & -0.568 & -10.291 & $<0.001$ & -0.044 & -0.030 \\
\hline $\mathrm{HbA1c}$ & 0.011 & 0.275 & 0.002 & 0.042 & 0.867 & -0.532 & 0.555 \\
\hline $\mathrm{HF}$ & -1.081 & 0.414 & -0.141 & -2.611 & 0.010 & -1.899 & -0.264 \\
\hline Hyperlipidemia & 0.494 & 0.406 & 0.063 & 1.217 & 0.225 & -0.307 & 1.295 \\
\hline COPD & 0.216 & 0.479 & 0.026 & 0.450 & 0.653 & -0.730 & 1.161 \\
\hline CKD & -1.111 & 0.480 & -0.139 & -2.316 & 0.022 & -2.059 & -0.164 \\
\hline
\end{tabular}

$B M I$ body mass index, $C K D$ chronic kidney disease, COPD chronic obstructive pulmonary disease, $D B P$ diastolic blood pressure, $H b 1 A c$ glycated hemoglobin, $H F$ heart failure, $H R$ heart rate, MoCA Montreal Cognitive Assessment, SBP systolic blood pressure

Our data indicate a primary role of diabetes and hypertension in the development of disability in a frail cohort of older adults. Furthermore, consistent with previous investigations [64, 65], in our population we observed a robust impact of age $(\mathrm{p}<0.001)$ and admission glycemia $(\mathrm{p}<0.001)$, strongly suggesting that glycemic control is a goal to achieve for avoiding adverse outcomes in this class of patients. Indeed, hyperglycemia worsens a delicate balance in patients with multimorbidity such as frail elders [66-68]. Since also female sex had a significant impact in our multivariate analysis, we speculate that frail elderly women with diabetes and hypertension might have a higher risk of atherosclerosis and cardiovascular diseases $[69,70]$, although this possibility needs to be verified in a dedicated trial.

Taken together, our data suggest that adding a simple evaluation with MoCA and gait speed test may be useful to evaluate cognitive and physical status. We propose to add an assessment of cognitive and physical condition in the comprehensive geriatric evaluation of frail hypertensive diabetic elders. Several limitations deserve consideration. We do not have follow-up records; nonetheless, we believe that observing significant differences is noteworthy, especially in a population of frail older adults. We used a classification of frailty that mainly assesses physical frailty, in contrast to a multidimensional approach also involving nutritional, and psychosocial components. Finally, the sample size of our group is relatively small; however, we had performed an a priori power analysis, based on our preliminary data, showing that the minimum estimated sample size to obtain statistically significant results was 151 patients.

\section{Conclusions}

This study is the first one to correlate MoCA score and $5-\mathrm{m}$ gait speed test in frail diabetic and hypertensive older adults. Further analyses with larger cohorts and a follow-up evaluation are warranted to corroborate our results.

\section{Abbreviations}

5mGS: 5-meter gait speed; BMI: Body mass index; CKD: Chronic kidney disease; COPD: Chronic obstructive pulmonary disease; Diabetes: Type 2 diabetes mellitus; DBP: Diastolic blood pressure; Hb1Ac: Glycated hemoglobin; HF: Heart failure; HR: Heart rate; MoCA: Montreal Cognitive Assessment; SBP: Systolic blood pressure.

\section{Authors' contributions}

PM, ADL and GS designed the study, analyzed data, drafted the manuscript, approved its final version, and made the decision to submit and publish the manuscript. JG, AL, and MM analyzed data, revised the manuscript's intellectual content, and approved the final version. AM, AP, SDG, MF, ALL, and SF acquired the data, revised the manuscript's intellectual content, and approved the final version. All authors have read and approved the final manuscript.

\section{Funding}

The Santulli laboratory is supported in part by the National Institutes of Health (R01-DK123259, R01-HL146691, R01-DK033823, R01-HL159062, and T32-HL144456 to G.S.), by the Diabetes Action Research and Education Foundation (to G.S.), by the Irma T. Hirschl and Monique Weill-Caulier Trusts (to G.S.), and by the American Heart Association (AHA-20POST35211151 to J.G.).

\section{Availability of data and materials}

Data and study materials are available from the First Author upon reasonable request. 


\section{Declarations}

\section{Ethics approval and consent to participate}

The Institutional Review Board of Campania Nord approved the protocol. Every patient has been included after the informed consent paper signed.

\section{Consent for publication}

All authors gave the consent for the publication of the article. All data and materials are available.

\section{Competing interests}

No competing interests.

\section{Author details}

${ }^{1}$ Department of Medicine, Einstein Institute for Aging Research, Einstein-Mount Sinai Diabetes Research Center (ES-DRC), The Fleischer Institute for Diabetes and Metabolism (FIDAM), Albert Einstein College of Medicine, New York, NY, USA. ${ }^{2}$ Department of Mental and Physical Health and Preventive Medicine, University of Campania "Luigi Vanvitelli", Naples, Italy. ${ }^{3}$ Division of Internal Medicine, Sant'Angelo Dei Lombardi Hospital, ASL (Local Health Unit), Avellino, Italy. ${ }^{4}$ International Translational Research and Medical Education (ITME) Consortium, Department of Advanced Biomedical Sciences, "Federico II" University, Naples, Italy. ${ }^{5}$ Elderly Assistance and Home Care, ASL (Local Health Unit), Avellino, Italy. ${ }^{6}$ Department of Molecular Pharmacology, Institute for Neuroimmunology and Inflammation (INI), Wilf Family Cardiovascular Research Institute, Albert Einstein College of Medicine, New York, NY, USA.

Received: 9 November 2021 Accepted: 30 December 2021

Published online: 19 January 2022

\section{References}

1. Draznin B, Aroda VR, Bakris G, Benson G, Brown FM, Freeman R, et al. Diabetes care in the hospital: standards of medical care in diabetes-2022. Diabetes Care. 2022;45(Suppl 1):S244-253.

2. Benetos A, Petrovic M, Strandberg T. Hypertension management in older and frail older patients. Circ Res. 2019;124(7):1045-60.

3. Yang $Y$, Hu X, Zhang Q, Zou R. Diabetes mellitus and risk of falls in older adults: a systematic review and meta-analysis. Age Ageing. 2016:45(6):761-7.

4. LeRoith D, Biessels GJ, Braithwaite SS, Casanueva FF, Draznin B, Halter JB, et al. Treatment of diabetes in older adults: an Endocrine Society* ${ }^{*}$ clinical practice guideline. J Clin Endocrinol Metab. 2019;104(5):1520-74.

5. Conroy SP, Westendorp RGJ, Witham MD. Hypertension treatment for older people-navigating between Scylla and Charybdis. Age Ageing. 2018;47(4):505-8.

6. Uchmanowicz B, Chudiak A, Uchmanowicz I, Rosinczuk J, Froelicher ES. Factors influencing adherence to treatment in older adults with hypertension. Clin Interv Aging. 2018;13:2425-41.

7. Williamson JD, Supiano MA, Applegate WB, Berlowitz DR, Campbell RC, Chertow GM, et al. Intensive vs standard blood pressure control and cardiovascular disease outcomes in adults aged $>/=75$ years: a randomized clinical trial. JAMA. 2016;315(24):2673-82.

8. Strain WD, Hope SV, Green A, Kar P, Valabhji J, Sinclair AJ. Type 2 diabetes mellitus in older people: a brief statement of key principles of modern day management including the assessment of frailty. A national collaborative stakeholder initiative. Diabet Med. 2018;35(7):838-45.

9. Ida S, Kaneko R, Imataka K, Murata K. Relationship between frailty and mortality, hospitalization, and cardiovascular diseases in diabetes: a systematic review and meta-analysis. Cardiovasc Diabetol. 2019;18(1):81.

10. Park SW, Goodpaster BH, Strotmeyer ES, Kuller LH, Broudeau R, Kammerer $C$, et al. Accelerated loss of skeletal muscle strength in older adults with type 2 diabetes: the health, aging, and body composition study. Diabetes Care. 2007;30(6):1507-12.

11. Clegg A, Hassan-Smith Z. Frailty and the endocrine system. Lancet Diabetes Endocrinol. 2018;6(9):743-52.

12. Aprahamian I, Sassaki E, Dos Santos MF, Izbicki R, Pulgrossi RC, Biella MM, et al. Hypertension and frailty in older adults. J Clin Hypertens (Greenwich). 2018:20(1):186-92.
13. Bromfield SG, Ngameni CA, Colantonio LD, Bowling CB, Shimbo D, Reynolds K, et al. Blood pressure, antihypertensive polypharmacy, frailty, and risk for serious fall injuries among older treated adults with hypertension. Hypertension. 2017;70(2):259-66.

14. Bursztyn M. Hypertension, its treatment, frailty, falls, and mortality. Hypertension. 2017;70(2):253-4.

15. Gorodeski EZ, Goyal P, Hummel SL, Krishnaswami A, Goodlin SJ, Hart LL, et al. Domain management approach to heart failure in the geriatric patient: present and future. J Am Coll Cardiol. 2018;71(17):1921-36.

16. Mantovani E, Zucchella C, Schena F, Romanelli MG, Venturelli M, Tamburin S. Towards a redefinition of cognitive frailty. J Alzheimers Dis. 2020;76(3):831-43.

17. Pilotto A, Rengo F, Marchionni N, Sancarlo D, Fontana A, Panza F, et al. Comparing the prognostic accuracy for all-cause mortality of frailty instruments: a multicentre 1-year follow-up in hospitalized older patients. PLoS ONE. 2012;7(1): e29090.

18. Wleklik M, Uchmanowicz I, Jankowska EA, Vitale C, Lisiak M, Drozd M, et al. Multidimensional approach to frailty. Front Psychol. 2020;11:564.

19. Patnode CD, Perdue LA, Rossom RC, Rushkin MC, Redmond N, Thomas $R G$, et al. Screening for cognitive impairment in older adults: updated evidence report and systematic review for the US preventive services task force. JAMA. 2020;323(8):764-85.

20. Clegg A, Young J, Iliffe S, Rikkert MO, Rockwood K. Frailty in elderly people. Lancet. 2013;381(9868):752-62.

21. Thillainadesan J, Scott IA, Le Couteur DG. Frailty, a multisystem ageing syndrome. Age Ageing. 2020;49(5):758-63.

22. Mone P, Pansini A. Gait speed test and cognitive decline in frail women with acute myocardial infarction. Am J Med Sci. 2020;360(5):484-8.

23. Fried LP, Tangen CM, Walston J, Newman AB, Hirsch C, Gottdiener J, et al. Frailty in older adults: evidence for a phenotype. J Gerontol A Biol Sci Med Sci. 2001:56(3):M146-56.

24. Mone P, Gambardella J, Pansini A, de Donato A, Martinelli G, Boccalone E, et al. Cognitive impairment in frail hypertensive elderly patients: role of hyperglycemia. Cells. 2021;10(8):2115. https://doi.org/10.3390/cells10082 115.

25. Solfrizzi V, Scafato E, Lozupone M, Seripa D, Schilardi A, Custodero C, et al. Biopsychosocial frailty and the risk of incident dementia: the Italian longitudinal study on aging. Alzheimers Dement. 2019;15(8):1019-28.

26. Guralnik JM, Ferrucci L, Simonsick EM, Salive ME, Wallace RB. Lowerextremity function in persons over the age of 70 years as a predictor of subsequent disability. N Engl J Med. 1995;332(9):556-61.

27. Srikanth V, Sinclair AJ, Hill-Briggs F, Moran C, Biessels GJ. Type 2 diabetes and cognitive dysfunction-towards effective management of both comorbidities. Lancet Diabetes Endocrinol. 2020;8(6):535-45.

28. Stringa N, van Schoor NM, Milaneschi Y, Ikram MA, Del Panta V, Koolhaas $C M$, et al. Physical activity as moderator of the association between APOE and cognitive decline in older adults: results from three longitudinal cohort studies. J Gerontol A Biol Sci Med Sci. 2020;75(10):1880-6.

29. Longo M, Bellastella G, Maiorino MI, Meier JJ, Esposito K, Giugliano D. Diabetes and aging: from treatment goals to pharmacologic therapy. Front Endocrinol (Lausanne). 2019;10:45.

30. Sinclair AJ, Rodriguez-Manas L. Diabetes and frailty: two converging conditions? Can J Diabetes. 2016:40(1):77-83.

31. Kirkman MS, Briscoe VJ, Clark N, Florez H, Haas LB, Halter JB, et al. Diabetes in older adults. Diabetes Care. 2012;35(12):2650-4.

32. Rodriguez-Manas L, Laosa O, Vellas B, Paolisso G, Topinkova E, OlivaMoreno J, et al. Effectiveness of a multimodal intervention in functionally impaired older people with type 2 diabetes mellitus. J Cachexia Sarcopenia Muscle. 2019;10(4):721-33.

33. Materson BJ, Garcia-Estrada M, Preston RA. Hypertension in the frail elderly. J Am Soc Hypertens. 2016;10(6):536-41.

34. Streit S, Poortvliet RKE, Gussekloo J. Lower blood pressure during antihypertensive treatment is associated with higher all-cause mortality and accelerated cognitive decline in the oldest-old. Data from the Leiden 85-plus Study. Age Ageing. 2018;47(4):545-50.

35. Folstein MF, Folstein SE, McHugh PR. "Mini-mental state". A practical method for grading the cognitive state of patients for the clinician. J Psychiatr Res. 1975;12(3):189-98.

36. Carpinelli Mazzi M, lavarone A, Russo G, Musella C, Milan G, D'Anna F, et al. Mini-mental state examination: new normative values on subjects in Southern Italy. Aging Clin Exp Res. 2020;32(4):699-702. 
37. Limongi F, Noale M, Bianchetti A, Ferrara N, Padovani A, Scarpini E, et al. The instruments used by the Italian centres for cognitive disorders and dementia to diagnose mild cognitive impairment (MCl). Aging Clin Exp Res. 2019;31(1):101-7.

38. O'Driscoll C, Shaikh M. Cross-cultural applicability of the Montreal Cognitive Assessment (MoCA): a systematic review. J Alzheimers Dis. 2017;58(3):789-801.

39. Nasreddine ZS, Phillips NA, Bedirian V, Charbonneau S, Whitehead V, Collin I, et al. The Montreal Cognitive Assessment, MoCA: a brief screening tool for mild cognitive impairment. J Am Geriatr Soc. 2005;53(4):695-9.

40. Afilalo J, Alexander KP, Mack MJ, Maurer MS, Green P, Allen LA, et al. Frailty assessment in the cardiovascular care of older adults. J Am Coll Cardiol. 2014;63(8):747-62.

41. Mone P, Gambardella J, Pansini A, Martinelli G, Minicucci F, Mauro C, et al. Cognitive dysfunction correlates with physical impairment in frail patients with acute myocardial infarction. Aging Clin Exp Res. 2021. https://doi.org/10.1007/s40520-021-01897-w.

42. Lilamand M, Dumonteil N, Nourhashemi F, Hanon O, Marcheix B, Toulza $\mathrm{O}$, et al. Gait speed and comprehensive geriatric assessment: two keys to improve the management of older persons with aortic stenosis. Int J Cardiol. 2014;173(3):580-2.

43. Afilalo J. Frailty in patients with cardiovascular disease: why, when, and how to measure. Curr Cardiovasc Risk Rep. 2011;5(5):467-72.

44. Afilalo J, Kim S, O'Brien S, Brennan JM, Edwards FH, Mack MJ, et al. Gait speed and operative mortality in older adults following cardiac surgery. JAMA Cardiol. 2016;1(3):314-21.

45. Afilalo J, Mottillo S, Eisenberg MJ, Alexander KP, Noiseux N, Perrault $L P$, et al. Addition of frailty and disability to cardiac surgery risk scores identifies elderly patients at high risk of mortality or major morbidity. Circ Cardiovasc Qual Outcomes. 2012;5(2):222-8.

46. Ganmore I, Elkayam I, Ravona-Springer R, Lin HM, Liu X, Plotnik M, et al. Deterioration in motor function over time in older adults with type 2 diabetes is associated with accelerated cognitive decline. Endocr Pract. 2020;26(10):1143-52.

47. Merchant RA, Goh J, Chan YH, Lim JY, Vellas B. Slow gait, subjective cognitive decline and motoric cognitive RISK syndrome: prevalence and associated factors in community dwelling older adults. J Nutr Health Aging. 2021;25(1):48-56.

48. Wallace SM, Yasmin, McEniery CM, Maki-Petaja KM, Booth AD, Cockcroft $\mathrm{JR}$, et al. Isolated systolic hypertension is characterized by increased aortic stiffness and endothelial dysfunction. Hypertension. 2007;50(1):228-33.

49. Santulli G. Is tirzepatide a new anti-hypertensive drug? N Engl J Med. 2022 (in press).

50. Nieuwdorp M, van Haeften TW, Gouverneur MC, Mooij HL, van Lieshout $\mathrm{MH}$, Levi $\mathrm{M}$, et al. Loss of endothelial glycocalyx during acute hyperglycemia coincides with endothelial dysfunction and coagulation activation in vivo. Diabetes. 2006;55(2):480-6.

51. Stirban A, Negrean M, Stratmann B, Gawlowski T, Horstmann T, Gotting $C$, et al. Benfotiamine prevents macro- and microvascular endothelial dysfunction and oxidative stress following a meal rich in advanced glycation end products in individuals with type 2 diabetes. Diabetes Care. 2006;29(9):2064-71.

52. Triggle $\mathrm{CR}$, Ding $\mathrm{H}$. A review of endothelial dysfunction in diabetes: a focus on the contribution of a dysfunctional eNOS. J Am Soc Hypertens. 2010;4(3):102-15.

53. Odegaard AO, Jacobs DR Jr, Sanchez OA, Goff DC Jr, Reiner AP, Gross MD. Oxidative stress, inflammation, endothelial dysfunction and incidence of type 2 diabetes. Cardiovasc Diabetol. 2016;15:51.

54. Shu J, Matarese A, Santulli G. Diabetes, body fat, skeletal muscle, and hypertension: the ominous chiasmus? J Clin Hypertens (Greenwich). 2019;21(2):239-42.

55. Kaur R, Kaur M, Singh J. Endothelial dysfunction and platelet hyperactivity in type 2 diabetes mellitus: molecular insights and therapeutic strategies. Cardiovasc Diabetol. 2018;17(1):121.

56. Qiu S, Cai X, Yin H, Sun Z, Zugel M, Steinacker JM, et al. Exercise training and endothelial function in patients with type 2 diabetes: a meta-analysis. Cardiovasc Diabetol. 2018;17(1):64

57. Wei J, Yin X, Liu Q, Tan L, Jia C. Association between hypertension and cognitive function: a cross-sectional study in people over 45 years old in China. J Clin Hypertens (Greenwich). 2018;20(11):1575-83.
58. Moheet A, Mangia S, Seaquist ER. Impact of diabetes on cognitive function and brain structure. Ann NY Acad Sci. 2015;1353:60-71.

59. Espeland MA, Lipska K, Miller ME, Rushing J, Cohen RA, Verghese J, et al. Effects of physical activity intervention on physical and cognitive function in sedentary adults with and without diabetes. J Gerontol A Biol Sci Med Sci. 2017;72(6):861-6.

60. Mattei J, Bigornia SJ, Sotos-Prieto M, Scott T, Gao X, Tucker KL. The Mediterranean diet and 2-year change in cognitive function by status of type 2 diabetes and glycemic control. Diabetes Care. 2019:42(8):1372-9.

61. Twig G, Tirosh A, Derazne E, Haklai Z, Goldberger N, Afek A, et al. Cognitive function in adolescence and the risk for premature diabetes and cardiovascular mortality in adulthood. Cardiovasc Diabetol. 2018;17(1):154

62. Li G, Prior JC, Leslie WD, Thabane L, Papaioannou A, Josse RG, et al. Frailty and risk of fractures in patients with type 2 diabetes. Diabetes Care. 2019;42(4):507-13.

63. Vetrano DL, Palmer KM, Galluzzo L, Giampaoli S, Marengoni A, Bernabei $\mathrm{R}$, et al. Hypertension and frailty: a systematic review and meta-analysis. BMJ Open. 2018;8(12): e024406

64. Lu YW, Chang CC, Chou RH, Tsai YL, Liu LK, Chen LK, et al. Gender difference in the association between TyG index and subclinical atherosclerosis: results from the I-Lan Longitudinal Aging Study. Cardiovasc Diabetol. 2021;20(1):206

65. Lee JH, Han K, Huh JH. The sweet spot: fasting glucose, cardiovascular disease, and mortality in older adults with diabetes: a nationwide population-based study. Cardiovasc Diabetol. 2020;19(1):44.

66. Della Corte V, Tuttolomondo A, Pecoraro R, Di Raimondo D, Vassallo $V$, Pinto A. Inflammation, endothelial dysfunction and arterial stiffness as therapeutic targets in cardiovascular medicine. Curr Pharm Des. 2016:22(30):4658-68.

67. Ostman C, Smart NA, Morcos D, Duller A, Ridley W, Jewiss D. The effect of exercise training on clinical outcomes in patients with the metabolic syndrome: a systematic review and meta-analysis. Cardiovasc Diabetol. 2017;16(1):110.

68. Tuttolomondo A, Petta S, Casuccio A, Maida C, Della Corte V, Daidone M, et al. Reactive hyperemia index ( $\mathrm{RHI}$ ) and cognitive performance indexes are associated with histologic markers of liver disease in subjects with non-alcoholic fatty liver disease (NAFLD): a case control study. Cardiovasc Diabetol. 2018;17(1):28.

69. Spence JD, Pilote L. Importance of sex and gender in atherosclerosis and cardiovascular disease. Atherosclerosis. 2015;241(1):208-10.

70. Halter JB, Musi N, McFarland Horne F, Crandall JP, Goldberg A, Harkless L, et al. Diabetes and cardiovascular disease in older adults: current status and future directions. Diabetes. 2014;63(8):2578-89.

\section{Publisher's Note}

Springer Nature remains neutral with regard to jurisdictional claims in published maps and institutional affiliations.

Ready to submit your research? Choose BMC and benefit from

- fast, convenient online submission

- thorough peer review by experienced researchers in your field

- rapid publication on acceptance

- support for research data, including large and complex data types

- gold Open Access which fosters wider collaboration and increased citations

- maximum visibility for your research: over 100M website views per year

At BMC, research is always in progress.

Learn more biomedcentral.com/submissions 